\title{
EX-POST EVALUATION OF THE FIRST GENERATION OF MUNICIPAL DEVELOPMENT PLANS - ISSUES AND CHALLENGES
}

\author{
V. Zarkov* \\ $\mathrm{PhD}$ candidate at the Department of Social and Economic Geography, Faculty of Geology and \\ Geography, Sofia University St. Kl. Ohridski, Sofia, Bulgaria
}

\begin{abstract}
The article presents the process of ex-post evaluation of the first generation of municipal development plans for the 2007-2013 period in six Bulgarian municipalities: Sliven, Tundzha, Bolyarovo, Bobov dol, Boynitsa and Lom, which are part of five administrative districts and three NUTS 2 planning regions. The article is based on six separate evaluations performed using a common methodology, allowing the formulation of generalized observations and conclusions as well as recommendations for the municipal plans for the 2014-2020 period.
\end{abstract}

Key words: regional development, monitoring and evaluation of public policies

Municipal Development Plans (MDP) are the main instrument for the implementation of regional development policy in the Republic of Bulgaria at the local (municipal) level, LAU $1^{1}$. The first generation of MDP covers the 2007-2013 period and has a duration of seven years. They were developed pursuant to the provisions of art. 13 of the Regional Development Act (RDA), which stipulates that the municipal plan defines the goals and priorities for development, as well as the financial resources for its implementation.

In accordance with the Methodological Guidelines for the Development of MDP as well as the Municipal Action Plan for Bulgaria's Accession to the EU 2004-2007 the objectives of each MDP are:

- to formulate a generally acceptable and desirable to the public vision for the development of the municipality over the next seven years given the new conditions resulting from the country's EU membership;

\footnotetext{
${ }^{1}$ Since the enactment of Regulation (EC) No $1059 / 2003$ of the European Parliament and of the Council, the common classification of territorial units for statistics (NUTS) has included only NUTS 0 to 3. NUTS 4 and NUTS 5 have been dropped from the latest version of the classification, and replaced by Local Administrative Units (LAU), respectively LAU 1 for municipalities and LAU 2 for settlements, which remain compliant with the NUTS codes.
}

- to analyze and motivate the evaluation overcome the negative processes and to mitigate the revealed weaknesses in the development;

- to outline the main directions in the different areas of the socio-economic development of the municipality by formulating and stating the most important priority tasks necessary for the "successful start" of the management under the new conditions;

- to identify measures for the implementation of the desired changes while using the available resources efficiently and protecting the environment;

- $\quad$ to mobilize and integrate the efforts of the various institutions and structures concerned with the socio-economic development;

- $\quad$ to inform the public of the identified problems and the ways to overcome them, and to adopt the recommendations of individuals, groups and communities, so that the plan can be the result of a broad consensus;

- $\quad$ to make strategic planning the major operational tool for the development of the municipality.

\footnotetext{
*Correspondence to: TENYO NIKOLOV MANOLOV, BULGARIA, PLOVDIV, 47, bul. Maritza, Tel:+359888809977., E-mail: t.manolov@mail.bg
} 
To ensure its ultimate success, the provisions of the MDP need to be viewed as a management tool in the hands of a functioning institution that would constantly monitor both the external influences and the processes inside the municipality, to analyze, define and propose the course of action (balanced, interdependent, equable development of all subsystems), within the development framework provided in the plan in order to achieve the set goals.

In this context, depending on the stage of implementation of the plan, the MDP is subject to three types of evaluation: ex-ante, mid-term and ex-post.

The regulatory framework that mandates an ex-post evaluation of the MDP is pursuant to the RDA and in particular to art. 34, para. 1 in conjunction with art. 9, item 7 , as well as art. 36 , para. 1 and para. 2. These provisions state:

- the requirement to do an ex-post evaluation of the MDP and the time of its implementation (art. 34 para. 1 in conjunction with art. 9, para. 7): "A ex-post evaluation of the implementation of the strategic planning documents under art. 9 item 7 (MDP) shall be performed not later than one year following expiry of the term of their validity.";

- the minimum scope and the contents of the ex-post evaluation (art. 34, para. 2): "The ex-post evaluation shall include:

1. assessment of the degree of attainment of objectives and of the sustainability of results;

2. assessment of the general impact;

3. assessment of the effectiveness and efficiency of the resources used;

4. conclusions and recommendations regarding the implementation of the regional and local development policy.";

- the responsibility for organizing and contracting of the ex-post evaluation (art. 36, para. 1): "Such assessments shall contracted out under the terms and procedure of the Public Procurement Act, by the Minister of Regional Development and Public Works, by district governors and by mayors of municipalities respectively.";

- $\quad$ the permitted sources of funds (art. 26) and their spending, including for monitoring and evaluation (art. 27, item 5);

- the definition of the documents related to the evaluation as official information in the public domain (art. 37, para. 1) as well as the respective requirements for providing the public with information (art. 37, para. 2);

- direction that the Regulations for the Application of the Regional Development Act define the minimum requirements for the selection of evaluators (art. 36, para. 2);

The Regulations for the Application of the Regional Development Act (RARDA) provide further details on the requirements in the RDA and link the implementation of the ex-post evaluation to:

- the requirements regarding information and publicity (art. 41), to be achieved by the preparation, discussion and publication pursuant to art 42, para. 1 of RARDA of a report presenting the output of the ex-post evaluation of the RDP implementation;

- $\quad$ the preparation of a document (art 42, para. 1) reporting the results of the of the expost evaluation and containing the results themselves;

- the definition of the minimum requirements for the selection of the experts performing the evaluations (art. 83, paras. 1 and 2);

- the requirement for the mayor of the municipality and the municipal council to provide information and publicity for the municipal development plan to the extent of their competencies (art 41).

The regulatory framework reviewed above provides a solid legal basis for the performance of ex-post evaluations, but it does not provide a definition either for the ex-post evaluation in general or for the ex-post evaluation of MDP in particular.

In the EU context the evaluation is understood as an assessment of the public involvement in development, with regard to the results, the impact and the needs that the intervention aims to meet. The evaluation is a systematic activity performed on the basis of objective standards and criteria, and it can be applied to a policy, plan, strategy, program or project. The main purpose of the evaluation is to improve the experience of the administration in the planning and implementation of public policies and programs, thus the main objectives of the evaluation are related to the planning, implementation and accountability. The evaluation is important for the identification of trends, monitoring of progress, stocktaking, correlation of actions to changing circumstances, meeting of new challenges, ensuring accountability, developing capacity through learning. All these functions of the evaluation are equally important, and they are not mutually exclusive. The main criteria used to achieve an objective evaluation are the criteria of relevance, validity, effectiveness, efficiency, impact and sustainability. 
Depending on the purpose of the evaluation, whether it is to improve planning, to verify compliance or to improve accountability, as well as the point in time when the evaluation is performed, it can be classified as ex-ante, midterm or ex-post.

The relationship between the various phases of MDP implementation and the types of evaluation is direct and makes it possible to:
- perform a preliminary impact evaluation for the MDP;

- measure progress in the process of implementation;

- balance the final effect against the projected results.

This relationship is graphically presented in the diagram below:

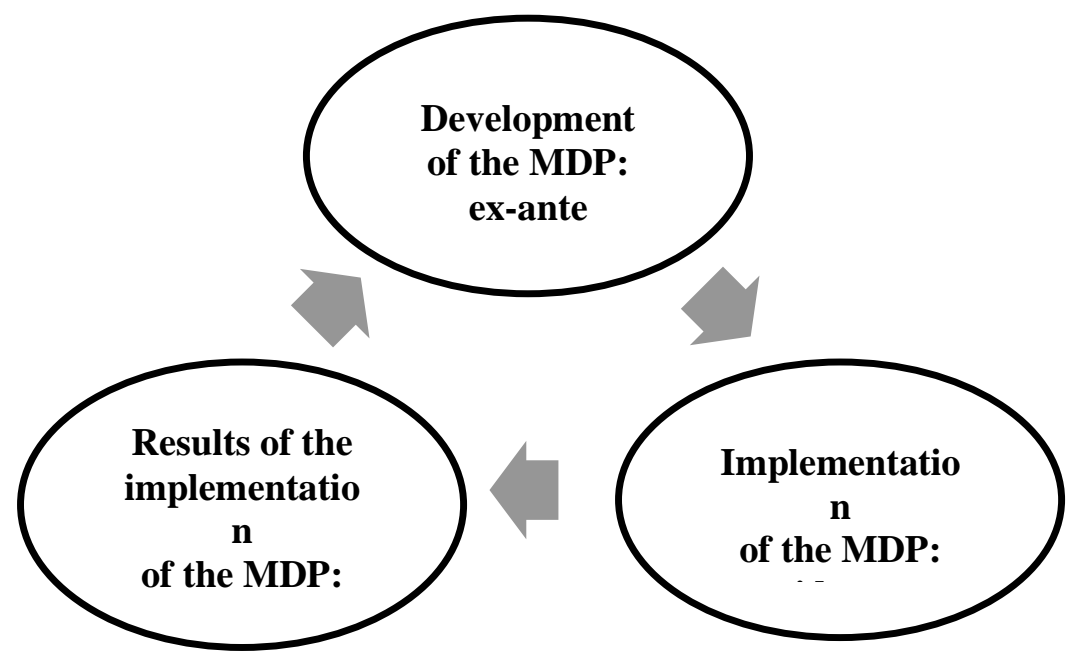

Diagram 1. Relationship between the main phases of the MDP and the types of evaluation

Evaluations follow the logic of MDP implementation. Preliminary evaluations (exante) help identify public needs, formulate MDP objectives and their proper targeting, taking into account the risks and challenges. They perform "diagnostic" functions by revealing their relevance and applicability and support their development. Intermediate (midterm) evaluations track the progress of implemented policies and the quality of their implementation. Retrospective (ex-post) evaluations focus on the results achieved and the impacts created.

In this evaluation cycle the ex-post evaluation is used for stocktaking of the overall MDP implementation, results achieved and the impacts created. It aims to find how the public resources have been used, what is the effectiveness of the interventions, and to what extent the projected goals have been achieved. An analysis is made of the factors for the success or the failure, the sustainability of the results and impacts.

In this respect, the main purpose of the ex-post evaluation of the six MDP was to provide a comprehensive view of their implementation and the realization of their strategic goals and priorities. The specific objectives of the expost evaluation were:
- to present the results of the implementation of the objectives and priorities set out in the MDP for the 2007-2013 period,

as well as the sustainability of the results achieved;

- to evaluate the effectiveness and efficiency of the use of financial resources for the achievement of the MDP objectives, including the use of the opportunities for funding from the national budget and the operational programs, as well as the management of their own funds (municipal budgets);

- $\quad$ to assist the municipal management bodies in the assessment of the MDP impact and the improvement of the planning process for the 2014-2020 period, taking into account both the progress made and any negative impact;

- to provide recommendations for the development of the second generation MDP;

- $\quad$ to ensure the required publicity of the ex-post evaluation results.

From the above-formulated objectives are derived the following main tasks for the performance of the ex-post evaluation:

- to collect and analyze the available information on the extent of the implementation the MDP for the 2007-2013 period as a whole and on individual measures, objectives and priorities; 
- $\quad$ to indicate which measures and targets are met - fully or partially, objectively dropped from MDP is currently implemented, etc.;

- $\quad$ to identify weaknesses and problems in the implementation of the MDP and to make recommendations concerning the 2014-2020 programming period

The guidelines of the European Commission as stated in The Resource for the Evaluation of Socio-Economic Development (EVALSED), September 2013, were used when choosing the methods for the evaluation. The following two main groups of methods were applied:

I. Methods of collecting and documenting information, analysis and study of documents, statistical grouping method and graphical method for visualising data, facts and trends through geometric images.

II. Methods for analyzing the collected documentation: expert panel, qualitative analysis, index method, comparative method and factor analysis.

The technological algorithm of the subsequent evaluation is based on a structured, systematic and iterative approach to collecting, processing, analyzing and presenting information and can be summarized as follows: 1. Development of an evaluation methodology. 2. Collection and evaluation of the initial data by examining the planning documents and reports on the implementation of the priorities and objectives of the MDP.

3. Processing, analysis and evaluation of key quantitative and qualitative data. The analysis and evaluation are performed on the basis of the achieved results, impact and overall effectiveness of the implementation of the MDP; effective and efficient use of the development resources on the territory of the municipality; political and social commitment, administrative and institutional capacity to implement policies for sustainable integrated regional and local development; sustainability of the results.

4. Presentation of the evaluation report to the mayor of the municipality, which is submitted for discussion and approval by the municipal council in accordance with art. 42, para 1 of RARDA.

The MDP for the six municipalities were developed in 2005-2006, and then discussed and passed by the Municipal Councils in 2006. The MDP state that their development was based on the requirements of the Regional Development Act of the Republic of Bulgaria (promulgated in the State Gazette, issue 14 of $20 / 02 / 2004$ and repealed in issue 50 of $30 / 05 / 2008$ of the State Gazette) and the regulatory framework effective at the time, including the Methodological Guidelines for the Development of Municipal Development Plans, enacted by Order of the Minister of Regional Development and Public Works No РД-02-14-12 of 11/01/2005.

After the adoption of the MDP significant changes occurred in the internal and external regulatory and institutional environment in which they had to be implemented and reported. In 2008 new national legislation in the field of regional development was passed, including a Regional Development Act and Regulations for its Application. The adoption of a new national legislative framework for regional development in Bulgaria was related to the new phase of harmonization of the national legislation with the EU legislation. The new RDA and the Regulations for its Application had to comply with the direct effect of European legislation in Bulgaria, as a member state of the European Union. In mid2009 the Methodological Guidelines for Updating Existing Strategies and Plans for Regional and Local Development were also enacted by Order of the Minister of Regional Development and Public Works No РД-02-14844 of $20 / 05 / 2009$.

From the analysis of the structure and content of the six MDP for the 2007-2013 period regarding their compliance with the latest Regional Development Act and its related regulatory framework, it is obvious that the plans did not fully meet the requirements of art. 13, para. 2 of the RDA. In some sections partial (incomplete, inaccurate, incorrect) data is provided. Whole sections are missing (Table 1).

In three of the six plans (Tundzha, Bolyarovo, Bobov dol) there are no sections describing the actions necessary to implement the principle of partnership and a provision for information and publicity. The Sliven MDP is missing a section describing the measures required for monitoring, evaluation and updating of the plan. The Boynitsa MDP has no indicative financial table of the resources required for implementation of the measures in each priority stated in the plan. No ex-ante evaluation was performed at the development phase for three of the six MDP (Bobov dol, Boynitsa and Lom). The remaining three MDP were subjected to an ex-ante evaluation. The recommendations produced by the evaluation were not reflected in the final versions of the MDP as approved by the municipal councils. 
The most significant issues with the six MDP that came to light during the ex-post evaluation are the following:

The strategic framework of all six MDP for 2007-2013 is too detailed and ambitious. The most extreme example in this regard is the Sliven MDP which contains an overall vision, 5 main priorities, 50 goals, 16 targets and 281 measures, and covers all public areas of local development that contribute to improving the quality of life - from technical infrastructure through business environment, social affairs, culture and education to public services. The situation is not much different with the other MDP.

Table 1. Compliance of the structure and contents of the six MDP with the requirements of art. 13, para. 2 of RDA

\begin{tabular}{|c|c|c|c|c|c|c|c|}
\hline № & REQUIREMENT & $\begin{array}{l}\text { Sliven } \\
\text { MDP }\end{array}$ & $\begin{array}{l}\text { Tundzha } \\
\text { MDP }\end{array}$ & $\begin{array}{c}\text { Bolyarovo } \\
\text { MDP }\end{array}$ & $\begin{array}{l}\text { Bobov } \\
\text { dol } \\
\text { MDP }\end{array}$ & $\begin{array}{l}\text { Boynitsa } \\
\text { MDP }\end{array}$ & $\begin{array}{l}\text { Lom } \\
\text { MDP }\end{array}$ \\
\hline 1. & $\begin{array}{l}\text { An analysis of the } \\
\text { economic and social } \\
\text { development of the } \\
\text { municipality }\end{array}$ & YES & YES & YES & YES & YES & YES \\
\hline 2. & $\begin{array}{l}\text { Municipality's } \\
\text { development goals and } \\
\text { priorities for a specified } \\
\text { period }\end{array}$ & partial & partial & partial & partial & partial & partial \\
\hline 3. & $\begin{array}{l}\text { An indicative financial } \\
\text { table summarizing the } \\
\text { resources required for } \\
\text { implementation of the } \\
\text { plan }\end{array}$ & YES & YES & YES & partial & NO & YES \\
\hline 4. & $\begin{array}{l}\text { Indicators for monitoring } \\
\text { and evaluation of the plan }\end{array}$ & partial & partial & partial & partial & partial & partial \\
\hline 5. & $\begin{array}{l}\text { Necessary steps pertinent } \\
\text { to the monitoring, } \\
\text { evaluation and updating } \\
\text { of the plan }\end{array}$ & $\mathrm{NO}$ & YES & YES & YES & YES & YES \\
\hline 6. & $\begin{array}{l}\text { Description of the } \\
\text { activities required for } \\
\text { application of the } \\
\text { principle of partnership } \\
\text { and ensuring information } \\
\text { and publicity }\end{array}$ & YES & NO & NO & NO & YES & YES \\
\hline 7. & $\begin{array}{l}\text { A program for } \\
\text { implementation of the } \\
\text { municipal development } \\
\text { plan }\end{array}$ & $\begin{array}{l}\text { NO (only } \\
\text { for 2007) }\end{array}$ & partial & partial & $\begin{array}{l}\text { NO (only } \\
\text { for 2007) }\end{array}$ & partial & partial \\
\hline 8. & $\begin{array}{l}\text { Ex-ante evaluation of the } \\
\text { plan }\end{array}$ & YES & YES & YES & NO & NO & NO \\
\hline
\end{tabular}

Obviously, it is impossible to resolve all problems faced by a municipality over a 7 -year period, and not only due to insufficient resources. This statement is prompted by the need for the ex-post evaluation to measure the achievements against the MDP projections and to quantify the degree to which the targets have been reached. Unrealistic targets inevitably distort the findings of the report and respectively the measurement of the level of progress. The cause for this is mostly due to unrealistically set targets in the development phase of the MDP. This in turn has been determined to a certain extent by the fact that during the planning period it was only possible to apply for European funding if the MDP already contained an entry proving the need and planned intervention. As a result, due to the lack of information at the time of the development of the six MDP (2005-2006) about what schemes would be opened at the national level and for which specifically the municipalities could apply, the MDP at that stage included projections to cover a maximum number of possibilities. The unclear situation in which the MDP were developed was confirmed by the fact that some of their targets showed overperfomance at the end of the 
reference period as compared to the projections in the indicative financial table, i.e. at the phase of MDP development the municipality had no information what EU funds it would be possible to obtain for the purpose of development.

All six municipalities have no practice to annually narrow down the MDP objectives in the form of annual programs for MDP implementation specifying the specific projects for implementation, the required financial resources and the responsible units. Such programs were developed in 2007 for the MDP of Sliven and Bobov dol. They stipulated that the evaluation of the annual program implementation was to be performed by specially established MDP monitoring groups. However, there are no reports on the implementation of either program. No annual programs for MDP implementation were prepared after 2007 in either municipality.

As the municipalities did not develop annual programs where the implementation of the measures was specified by years as individual projects (activities), by financial resources and by funding sources, with a few exceptions, it is difficult to quantify the degree of implementation of the MDP targets against the set deadlines. It is also difficult to evaluate the effectiveness and efficiency of expenditure since there is no quantitative data on the funding of the individual measures by year. The lack of such data creates additional difficulties when evaluating the degree of implementation of the MDP targets to make an objective assessment whether the absence of activities (projects) under specific measures for some of the years is a case of non-performance or not. The implementation timeframe for the MDP measures is also worth noting. For some measures it is set within the span of a specific year. In most cases however, it covers a longer period of time or the entire 2007-2013 period, so it is difficult to determine what progress was made towards reaching a target over a given time period.

Another difficulty in performing the ex-post evaluation was created by the fact that the indicative financial table did allocate funding for the implementation of all measures under the individual MDP priorities, making it difficult to evaluate intended versus achieved performance. An example of this is MDP Bobov dol.

For the purpose of the evaluation of the socioeconomic impact of the six MDP on the economic, social and environmental situation in the municipalities, the RDA requires the application of a system of indicators measuring the progress towards the MDP's targets, the financial performance and the degree of achievement of the projected results based on the projects implemented under the priorities and goals of the MDP. At the MDP development phase the indicators should be formulated in such a way as to be easily, clearly and precisely "recognizable", to give the most accurate and comprehensive quantitative or qualitative picture of the phenomenon to which they relate. Rather than being abstract concepts the indicators should have a specific quantified expression numbers, tons, meters, acres, BGN, etc. In order to ensure full transparency and traceability of the measuring progress, of the monitoring, control and measurement of the targets and operations, it is necessary to establish quantitative indicators with specific values. It is also desirable that qualitative indicators be indicated and specified into detailed, clearly visible, quantitative effects. Only the indicators that meet these requirements would create favourable conditions to perform objective and at the same time highly informative evaluations of the state, structure and dynamics of the assessed objects and phenomena, or in this case the territory of the six municipalities.

In this sense, the indicators measuring the achievability of the targets of the six MDP do not fully meet these requirements. In four of the six MDP (Sliven, Bobov dol, Lom and Boynitsa) the indicators were not put into distinct categories - output, result and impact indicators. In all six MDP there are no baseline and target values of the proposed indicators. For some municipalities (Bobov dol, Bolyarovo and Boynitsa) additional difficulty arises from the fact that the indicators were not divided and grouped consecutively for the respective priorities, goals and measures but were presented as a combined list appended to the MDP. Thus, in practice the planned indicators in the six MDP cannot be properly used in the ex-post evaluation.

Another drawback in the performance of the ex-post evaluation stems from the fact that, as a whole, in the six municipalities there is no efficiently functioning system for permanent monitoring and control over the MDP implementation. There are no regular annual reports and reports on the MDP implementation (with the exception of Lom), which are a legal requirement under art. 91 of the RARDA. In most cases, the main 
information source for monitoring the MDP implementation is a kind of a $\log$ of the projects under development, their progress and implementation. The maintenance of this $\log$ proved a hard task as there was no work organization and commitment by stakeholders to submit in a timely manner reliable, accurate and correct information for its maintenance.

Based of the six ex-post evaluations and the difficulties encountered in their performance the following recommendations for the second generation of MDP can be made:

The MDP should be developed in accordance with art. 13, para. 2 of the Regional Development Act and in strict compliance with the structure set out in the Methodological Guidelines for their development, enacted by Order No РД-02-14-2402 of 22/11/2011 of the Minister of Regional Development and Public Works.

The strategy developed by the municipalities should take into account the key policies established in national, regional and district documents for regional development, but to adapt them to the factors, conditions and potential for development of the municipality, the network of settlements, separate sectors, etc. and to focus on a limited number of priorities and measures that could realistically be implemented over the seven-year period of the plan by 2020 .

In the development of the indicative financial table and the inclusion of specific projects it would be better to apply the following approach: 1) to have a secure source of funding for each project; 2) to include in the MDP only projects whose implementation depends on the municipal administration and local government, i.e. the municipality, and not another entity should be eligible for funding; 3) the projects should contribute to the achievement of the plan's specific objectives, and thus to the implementation of its priorities and strategic goals. In this way the indicative financial table will include only projects that depend on the available resources, currently existing funding sources, and not least the potential of the territory for their successful implementation, so that the planning corresponds to the capacities rather than to desires and needs.

As per the instructions in EVALSED: The Resource for the Evaluation of SocioEconomic Development, September 2013, the MDP for 2014-2020 should use three groups of indicators: result indicators, output indicators and impact indicators. The indicators should be measurable, specific, relevant and time- dependent. Each indicator should be provided with an adequate and reliable source of information that can be used if necessary to establish the current state at a given point in time. Baseline and target values are set for each indicator, as well as a reporting period. The sources of information for monitoring indicators must be reliable and readily available.

The MDP for 2014-2020 should contain measures for the creation and implementation of an administrative mechanism for the collection and aggregation of information and documentation related to the MDP implementation in order to ensure its correctness and accuracy in analyzing and taking management decisions by the mayor of the municipality and the municipal council respectively, and in accordance with art. 91 of the RARDA.

In conclusion it should be pointed out that the quality of the evaluation process (in this case ex-post evaluation) is directly dependent on the quality of the planning and programming of the MDP. The more thorough and clearly parameterized the overall process of preparing the document is, the more information will be transferred to the evaluation procedure and it will give a higher variability of the process, and respectively more and better solutions to the problems and more efficient ways to overcome the weaknesses of the document.

Acknowledgements: This article summarizes the results of six separate projects for the preparation of ex-post evaluations of MDP funded under Administrative Capacity Operational Programme 2007-2013, Priority Axis I "Good governance", Sub-priority 1.3 "Effective coordination and partnership in the development and implementation of policies". Further information on the results of the evaluations can be found at: http://www.sliven.bg; http://www.tundzha.net; http://bolyarovo.eu; http://www.bobovdol.eu; http://oalom.acstre.com; http://obshtinaboinica.com.

\section{REFERENCES}

1. Regional Development Act, entered into force on $31 / 08 / 2008$, promulgated in the State Gazette, issue 50 of 30/05/2008, latest amendment promulgated in the State Gazette, issue 9 of 03/02/2015;

2. Methodology for the Implementation of a Mid-term Evaluation of the Regional Development Strategy, MRDPW, Sofia, 2010;

3. Methodological Guidelines for Updating Existing Strategies and Plans for Regional 
and Local Development, enacted by Order of the Minister of Regional Development and Public Works No РД-02-14-844 of 20/05/2009;

4. Methodological Guidelines for the Development of MDP for 2004, enacted by Order of the Minister of Regional Development and Public Works No РД-0214-12 of 11/01/2005;

5. Methodological Guidelines for the Development of MDP for 2014-2020, enacted by Order of the Minister of Regional Development and Public Works No РД-02-14-2402 of 22/11/2011;

6. Municipal Action Plan for Bulgaria's Accession to the EU 2004-2007 adopted by the General Assembly of NAMRB on 09/07/2004;

7. Municipal Development Plan for the period 2007-2013 of Sliven, Tundzha, Bolyarovo, Bobov dol, Boynitsa and Lom Municipalities;

8. Regulations for the Application of the Regional Development Act, entered into force on 31/08/2008 г. promulgated in the State Gazette, issue 80 of 12/09/2008, latest amendment promulgated in the State Gazette, issue 102 of 12/12/2014;

9. EVALSED: The Resource for the Evaluation of Socio-Economic Development, September 2013. 